\title{
BRANCHED ALKANES FROM \\ BLUE-GREEN ALGAE
}

\section{RECEIVT-} LAWREN:

RADIATION LL:

SEP 301970

Jerry Han and Melvin Calvin

\section{LIBRARY}

DOCUMENTS SELTIC:

August 1970

AEC Contract No. W-7405-eng-48

\section{TWO-WEEK LOAN COPY}

This is a Library Circulating Copy

which may be borrowed for two weeks.

For a personal retention copy, call

Tech. Info. Division, Ext. 5545

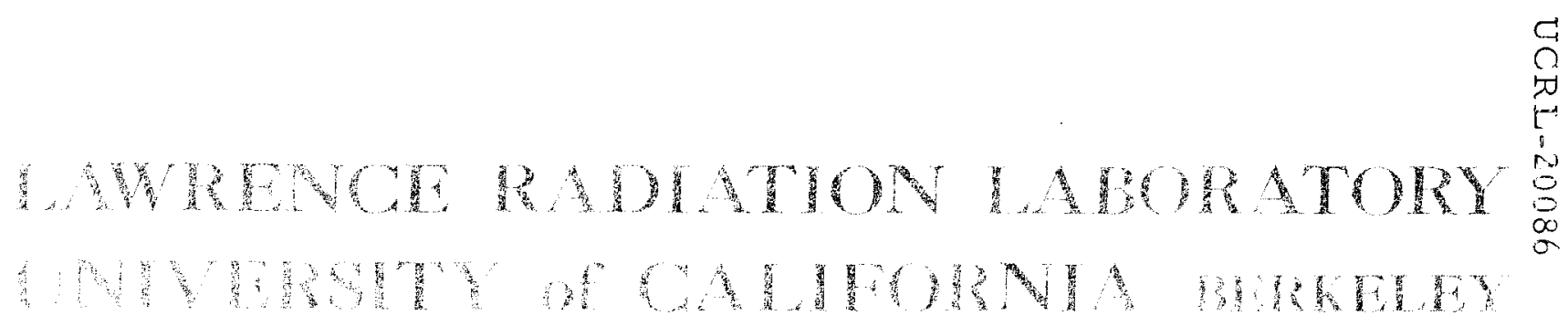




\section{Branched Alkanes From Blue-Green Algae}

by Jerry Han and Melvin Calvin

Department of Chemistry, Space Sciences Laboratory and Laboratory of Chemical Biodynamics, University of

California, Berkeley, California 94720

Summary: Branched alkanes from blue-green algae were separated on a

750 feet high resolution capillary gas chromatographic column. The mixture

was found to be $90 \%$ of 1:1 ratio 7-methyl, and 8-methyl-heptadecane, and 10\%

of 6-methylheptadecane. An optical rotation of $+2.5 \pm 0.5$ was obtained on

a $5 \mathrm{mg}$ of mixture. 
The hydrocarbon composition of the blue-green algae is apparently very simple. ${ }^{1-4}$ The pattern shows normal hydrocarbons in the $c_{15}$ to $c_{20}$ range with a predominance of $n-C_{17}$. The isoprenoid hydrocarbons, pristane $(2,6$, 10,14 -tetramethylpentadecane), and phytane $(2,6,10,14$-tetramethylhexadecane) are absent in algae, but are generally present in higher plants and animals. Bloch ${ }^{4}$ reported the absence of sterols in procaryotic cells. However, Reitz and Hamilton ${ }^{5}$ isolated two sterols from blue-green algae in small amount. Their results showed that very harsh methods had to be used to extract the sterols from the algae, suggesting that sterols might be bound very tightly within the procaryotic cells.

Methyl-branched alkanes seemed to be of particular significance because the methy 1 branches are not iso- and anteiso-structures. They appear to occur uniquely in blue-green algae and are absent from photosynthetic and non-photosynthetic bacteria. 6 These hydrocarbons have not been found in the green algae, ${ }^{2,6}$ which are more advanced than blue-green algae, but are still relatively primitive.

Instrumental analyses and synthesis of 7,9-dimethylhexadecane and of 7- and 8-methylheptadecanes proved that the branched hydrocarbon first found consisted of a mixture $(1: 1)$ of 7 - and 8-methylheptadecane, which previously could not be separated by g.1.c. ${ }^{2}$ The incubation of L-m.ethionine-methyl- ${ }^{14} \mathrm{C}$ and tritiated cis-vaccenic acid (cis- $\Delta "-C_{18}$ acid) to form 7- and 8-methylheptadecane indicated that the methionine methyl group was specifically added to the double bond of vaccenic acid. This was followed by decarboxylation to yield the 7- and 8-methylheptadecane. 
We now describe a further identification and optical activity measurement of the branched- $C_{18}$ hydrocarbons from blue-green algae. The dried cells (Nostoc muscorum) were treated with $3: 1$ benzene and methanol. The extracted material was transferred to the top of an alumina column previously washed with n-heptane; it was then eluted with three solvents, $n$-heptane, benzene, and methanol. The first fraction (n-heptane fraction) containing the total aliphatic hydrocarbons, was used for the following analyses. The total aliphatic hydrocarbon fraction $(2 \mu \mathrm{g})$ was analyzed on an Aerograph Model 204 gas chromatograph equipped with the high resolution capillary column and flame fonization detector. A high resolution v.p.c. column, $750 \mathrm{ft}$., 0.02 inch inside diameter, was made in this laboratory. It was coated with $5 \%$ of $1: 1$ Igepal $\mathrm{C} 0-880^{8}$ and GE SF $-96^{9}$ in ether and acetone. The column exhibited efficiencies in excess of 350,000 theoretical plates for branched- $C_{18}$ peaks eluting after 12 hours.

The branched $\mathrm{C}_{18}$ hydrocarbon mixture was indeed separated into equal amounts of 7-methylheptadecane (Figure, peak ' $b^{\prime}$ ) and 8-methylheptadecane (Figure, peak ' $a$ '). However, approximately $10 \%$ of peak ' $c$ ' was also separated by this high resolution v.p.c. Peak ' $c$ ' was identified as 6-methylheptadecane by its mass spectrum. The mass spectrum was taken using a combination of an Aerograph 204 gas chromatograph and an A.E.1. MS-12 mass spectrometer.

Five mg. of total branched- $C_{18}$ hydrocarbons were isolated from the total aliphatic hydrocarbon fraction obtained from $30 \mathrm{gms}$. of dried cells by preparative v.p.c. on an Aerograph Model A-90-P. The total hydrocarbon fraction was chromatographed on a temperature-programmed $25 \mathrm{ft} . \times 0.25$ in $3 \% \mathrm{SE}-30$ column. The 
optical activity was studied on an ETL-NPL-Automatic Polarimeter Type 143A, with the sodium D line, $10 \mathrm{chm}$ load, $5 \mathrm{~cm}$ cell length, and $90 \mathrm{mv}$ scale. An optical rotation of $+2.5 \pm 0.5$ was obtained on a n-hexane solution at $20^{\circ} \mathrm{C}$. We therefore believe that the enzymic methylation of cis-vaccenic acid was a stereospecific reaction. It is entirely possible that the methyl group could be added stereospecifically on the open side of the double bond. The methylation reaction was followed by decarboxylation to yield the optically active branched- $\mathrm{C}_{18}$ hydrocarbons. No further attempt has yet been made to designate the exact stereochemistry or absolute configuration at the asymmetric center.

This work was supported in part by the National Aeronautics and Space Administration, grant NSG 05-003-003, and in part by the U.S. Atomic Energy Commission.

\section{REFERENCES}

1. J. Han, E.0. McCarthy, W. VanHoeven; M. Calvin, \& W.H. Bradley, Proc. Nat'1. Acad. Sci. 59, 29 (1968).

2. J. Han, E.D. McCarthy, M. Calvin and M.H. Benn, J. Chem. Soc. (c) 2785 (1968).

3. P.L. Parker, C. Van Baalen, and L. Maurer, Science, 155, 707 (1967).

4. K. Bloch, in "Evolving Genes and Proteins" Eds. V. Bryson and H.J. Vogel, Academic Press, New York (1965).

5. R.C. Reitz and J.G. Hamilton, Comp. Biochem. Physiol. 25, 401 (1968).

6. J. Han and M. Calvin, Proc. Nat'1. Acad. Sci., 64, 436 (1969).

7. J. Han, H.W-S. Chan, and M. Calvin, J. Amer. Chem. Soc. 91, 5156 (1969).

8. Nonylphenoxypoly (ethyleneoxy)-ethanol, from General Antline and Film Corporation, Ney York. N.Y.

9. Methyl silicone fluid, from the General Electric Company, Waterford, New York, N.Y. 
Figure : Gas cliromatographic separation of branched- $\mathrm{C}_{18}$ hydrocarbons. A stainless steel tubing $750 \mathrm{ft} . \times 0.02 \mathrm{in}$. coated with $50 \%$ IgepalC0-880 and 50\% of GE SF-96. Aerograph model 204 gas chromatograph was equipped with a flame ionization detector. Helium pressure 30 psi, no split. Isothermal at $125^{\circ} \mathrm{C}$. Peaks $a, b$, and $c$ were identified as 8-methyheptadecane, 7-methylheptadecane, and 6-methylheptadecane, respectively by GC-MS.

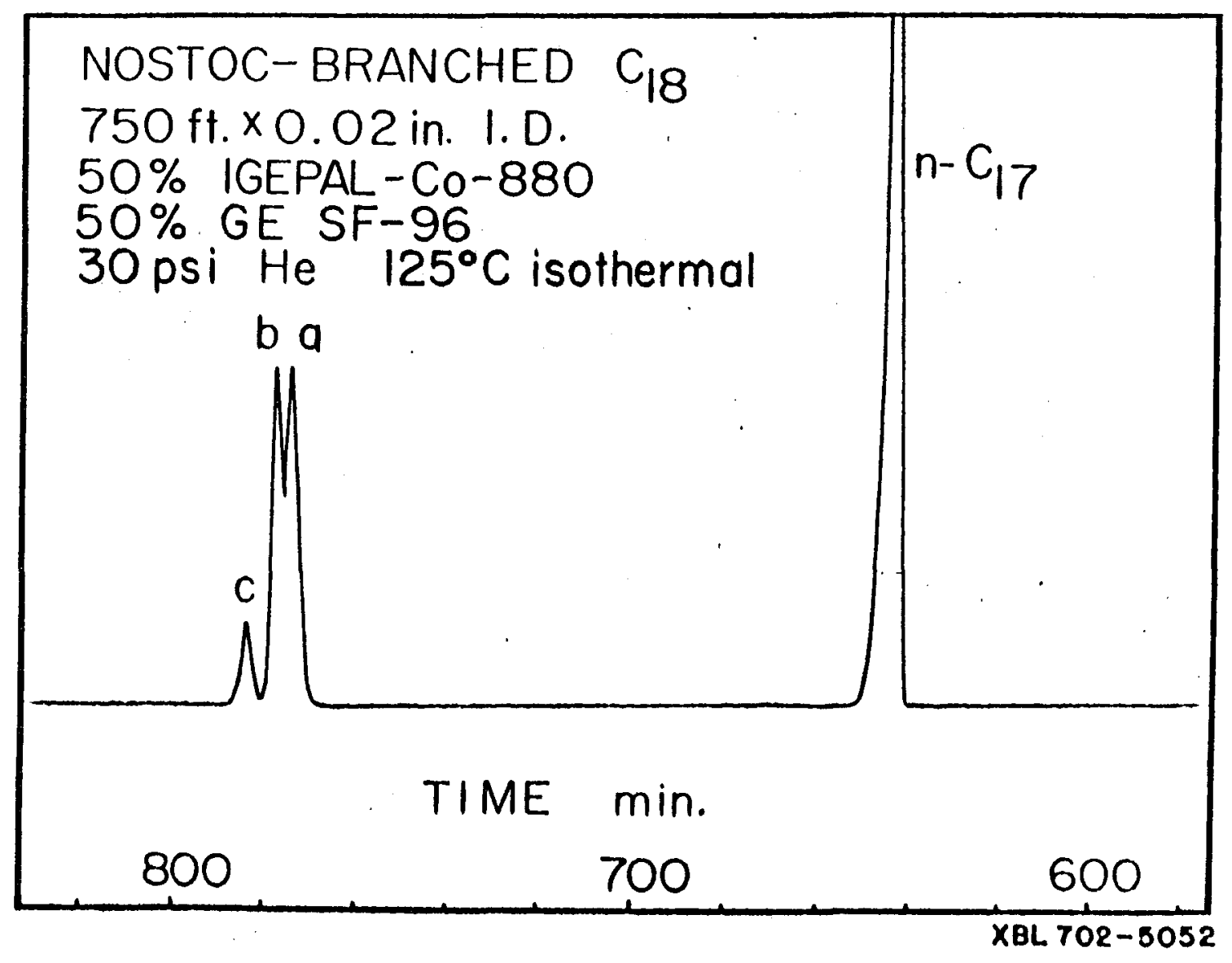

